\title{
Investigation on Seroprevalence of Mycoplasma Gallisepticum Infection in Commercial Layer Farms in Rajshahi District Using Rapid Serum Plate Agglutination Test
}

\author{
Aurangazeb Kabir, Md. Obaidullah Al Masum, Most. Sabina Yasmin, Md. Golam Sarwar, Md. \\ Shamim Hossain, Md. Emtiaj Alam, Soshe Ahmed, and Mohammad Mahbubur Rahman
}

\section{ABSTRACT}

\begin{abstract}
Mycoplasma gallisepticum (MG) infection is very common in birds that cause respiratory infections in chickens, turkeys, and other avian species. It has brought about a considerable amount of financial losses to the poultry sector in Bangladesh. We conducted a study on the Seroprevalence of MG infection in two different geographical areas of Bangladesh under Rajshahi district, namely Paba and Bagmaraupazila. 800 sera samples were collected and tested with Rapid Serum Plate Agglutination Test (RSA) to identify the MG antibodies using commercial Mycoplasma gallisepticum antigen. The gross Seroprevalence of MG infection was $59.25 \%$ in the study area. The maximum rate $(68.80 \%)$ of infection was found in the winter season, followed by the summer season $(49.36 \%)$. The result further revealed that the condition was higher $(69.01 \%)$ in larger-sized flocks than in small $(53.63 \%)$. We noticed that younger birds having 10-20 weeks of age are more prone to be affected with avian mycoplamosis with an infection rate of $72 \%$ compared to their adult counterpart of $71+$ weeks with $52 \%$ morbidity. Our study revealed that Mycoplasma gallisepticum infection is prevalent in Paba and Bagmaraupazila in Rajshahi. The farms should take strict bio-security measures to mitigate this infection in the mentioned areas. Proper medications for the affected birds and timely prophylactic measures for the healthy ones could be practical and preventive strategies against avian mycoplasmosis. Amid limitations, we conducted our experiments, and thus further research is warranted to substantially assess and validates our observations.
\end{abstract}

Keywords: Seroprevalence, Commercial Poultry, Mycoplasma Gallisepticum Infection, Serum Agglutination Test.
Submitted :June 22,2021

Published : July 14,2021

ISSN: $2684-1827$

DOI: 10.24018/ejfood.2021.3.4.331

\section{Aurangazeb Kabir}

Associate Professor, Dept. of Veterinary and Animal Sciences, University of Rajshahi, Rajshahi-6205, Bangladesh.

(e-mail: aurangak@yahoo.com)

Md. Obaidullah Al Masum

Dept. of Veterinary and Animal Sciences, University of Rajshahi, Rajshahi-6205, Bangladesh.

(e-mail: oalmasum93@gmail.com)

Most. Sabina Yasmin

Dept. of Veterinary and Animal Sciences, University of Rajshahi, Rajshahi-6205, Bangladesh.

(e-mail: sabinayasmin12208306@ gmail.com)

Md. Golam Sarwar

Dept. of Veterinary and Animal Sciences, University of Rajshahi, Rajshahi-6205, Bangladesh.

(e-mail:

golam.sarwar12038314@gmail.com)

\section{Md. Shamim Hossain}

Dept. of Veterinary and Animal Sciences, University of Rajshahi, Rajshahi-6205, Bangladesh.

(e-mail: shamimdvm453@gmail.com)

Md. Emtiaj Alam

Associate Professor, Dept. of Veterinary and Animal Sciences, University of Rajshahi, Rajshahi-6205, Bangladesh.

(e-mail: emtiajalam8303@gmail.com) Soshe Ahmed

Associate Professor, Dept. of Veterinary and Animal Sciences, University of Rajshahi, Rajshahi-6205, Bangladesh.

(e-mail: soshe.ahmed@gmail.com) Mohammad Mahbubur Rahman* Professor, Dept. of Veterinary and Animal Sciences, University of Rajshahi, Rajshahi-6205, Bangladesh.

(e-mail: mmrahman ${ }^{\circledR}$ ru.ac.bd)

*Corresponding Author 


\section{INTRODUCTION}

Infectious diseases, especially bacterial and viral, generate major health problems for the poultry industry's proper growth and development. Mycoplasma gallisepticum is considered an essential deleterious microorganism in layer birds that causes financial losses [1], [2]. Significant losses in chickens can be caused by economically significant pathogen Mycoplsma, which causes feed efficiency, decreased growth, lower egg production as well as production of inferior quality carcasses. It's likely that the carcasses of slaughtered birds will be downgraded. This organism has been eradicated from commercial poultry breeding flocks in many countries with modern poultry operations. However, in many other poultry operations, it can still be a concern, such as multi age layer flocks, game bird raising facilities and backyard birds [3].

In terrestrial poultry, Mycoplasma gallisepticum is one of the most important agents which belongs to the family Mycoplasmataceae (class Mollicutes, order Mycoplasmatales). This organism comes in a variety of strains, which can have varying degrees of virulence and host preferences. The house finch lineage is a distinct that has become established in wild birds after diverging significantly from poultry strains. Some pathogenic strains of mycoplasmas in poultry include M. synoviae, M. meleagridis and M. iowae. Avian mycoplasmosis is the name given to the diseases they cause, but the clinical symptoms vary [4]. Pleuropneumonia like species emerged as other pathogenic and saprophytic isolates from veterinary and human sources accumulated. Mycoplasma (Greek: mykes, fungus plasma, moulded) refers to the filamentous (fungus-like) nature of certain species' cells, as well as the plasticity of the outer membrane, which results in pleomorphism [5]. Mycoplasmas, for example, are the tiniest prokaryotic species that can develop in a cell-free culture medium. Humans, animals, plants, insects, dirt, and sewage all contain them. The first mycoides spp. was isolated from pleuropneumoniastricken cattle in 1898. Chickens, turkeys, and other game birds are all affected by M. gallisepticum such as ring necked pheasants (Phasianuscolchicus), chukar partridges (Alectorisgraeca), redlegged partridges (Alectorisrufa), grey partridges (Perdixperdix), bobwhite quail (Colinusvirginianus), Japanese quail (Coturnixjaponica) and peafowl (Pavocristatus). This organism has also been detected in ducks and geese, although it does not seem to be a significant pathogen in waterfowl. Pet or hobby birds are also affected, which are symptomatic yellow napped Amazon parrots (Amazonaauropalliata) and asymptomatic pigeons (Columba livia) [6].

Respiratory and ocular secretions, eggs and semen are the source of M. gallisepticum. M. gallisepticum which are in the egg and debris from broken eggs may be a source of the organism for the poultry and other birds. Egg borne transmission is more frequent in birds infected during laying than in birds infected before they mature. Long term asymptomatic carriage has been reported in poultry, some game birds and house finches. When birds are in a stressed condition, they develop clinical signs. M. gallisepticum can be spread by fomites and can survive for many days in the atmosphere. Some substrates, such as feathers and the contents of eggs, have been documented to have a higher rate of survival. This organism was found to survive for a day or two on human skin and one day on bird feeders. Mycoplasmas can survive in the environment by forming biofilms. The amount of biofilm generated by different strains varies [7].

Illnesses which are induced by $\mathrm{M}$. gallisepticum are possible to diagnose by isolating the organism from clinical samples or detecting nucleic acids by means of PCR, and flock serology. Loop mediated isothermal amplification assays have also been published. In mycoplasma free chicken embryos or chicken, MG can be retrieved; however, since the invention of PCR, this method has been seldom used. The colonal cleft, oropharynx, conjunctiva, infraorbital sinus, nasal cavity, esophagus, trachea, air sacs, and lungs are all typical sampling sites for culture and PCR. Swabs from the cloaca and phallus, as well as embryonated eggs, dead in shell embryos, and chicks or poults that have broken the shell but failed to hatch, can all contain organisms. Postmortem samples should be collected from recently dead animals or carcasses frozen soon after death. Frey's medium is the media through which MG can be isolated. It is not always easy to bounce back. To recognize cultured species, indirect immunofluorescence, immunoperoxidase staining, a growth inhibition procedure, metabolism inhibition, and PCR or other DNA methods are used. Biochemical tests can be helpful in the early stages of diagnosis. It may be difficult to tell the difference between M. gallisepticum and M. imitans, a species that is more commonly found in ducks and geese. If M. imitans is suspected, tests such as PCR restriction fragment length polymorphism (PCR-RFLP) or immunofluorescence using serial dilutions of antisera to the two organisms in parallel may be used to differentiate the two species.

The disease's microscopic lesions (multifocal parenchymal necrosis, meningitis, perivascular cuffing, and vasculitis) have been identified as consistent and distinct. Serology is particularly useful when it comes to screening in poultry flocks. Individual birds are less useful since non-specific reactions are normal in some studies. A rapid serum agglutination (RSA) test, ELISAs, and hemagglutination inhibition are examples of widely used assays. The hemagglutination inhibition test is more specific than the RSA test, which can produce false positives, but it is also strain specific and less sensitive. Other serological tests have been identified or used [8].

Thus, we examine the Seroprevalence of MG infection's current situation regarding age, season, and flock sizes in commercial layer chickens at two different areas in the western part of Bangladesh (Rajshahi district) using RSA.

\section{METHODOLOGY}

\section{A. Location of the Study Area}

This study was conducted in two different sites: The Laboratory of Quality feeds Limited and Paba and Baghmaraupazila of Rajshahi, Bangladesh. Geographically Rajshahi is situated within Barind Tract at $23 \mathrm{~m}$ above sea level, where the divisional city centre stands upon the northern alluvial plains of the Padma River [9]. 


\section{B. Sampling}

800 blood samples were collected from the wing vein of unvaccinated and healthy chickens from January 2018 to May 2019. The sampling considered the age group, seasons (summer and winter), Flock size, and region.

\section{Data Collection}

Some information about qualitative variables (geographical area of flocks, seasons, commercial strain of layer type, present of maternal antibodies against MG, any vaccination against $\mathrm{MG}$ administered in their parent flocks) and quantitative variables (farm capacity, egg production rate, house number, flock age) were gathered from each farm to be calculated for correlation.

\section{Preparation of Sera Samples}

Blood samples were obtained aseptically from the wing vein of the selected birds using $5 \mathrm{ml}$ sterile disposable syringe and needles. The blood caused the syringe to coagulate and was kept for 1-2 hours at room temperature. After clotting, a clean straw colored serum was seen around the clotted clump, sera were separated, centrifuged and poured in sterile vials, labeled individually and stored at $4^{\circ} \mathrm{C}$ until used.

\section{E. Mycoplasma Antigen}

Standard Mycoplasma gallicepticum (MG RSACevaBiovac) antigen purchased from Biolab Company Ltd. Bangladesh was used for Rapid Slide Agglutination (RSA) test for the detection of $M$. gallisepticum antibodies in the sera samples.

\section{F. Rapid Serum Plate Agglutination Test (RSA)}

Rapid tests were carried out at $25^{\circ} \mathrm{C}$ and within 24 hours of collection of sera. The RSA test was performed by crystal violet stained commercial MG RSA-CevaBiovac antigen. For this test $0.02 \mathrm{ml}$ antigen and $0.2 \mathrm{ml}$ serum was mixed thoroughly on a glass plate. In positive cases, agglutination was noticed within 2 minutes of gentle rocking. However, in negative cases, such a phenomenon was not evident. To calculate the prevalence agglutination strengths were scored from $(0)$ to $(+++)$ (Fig. 1). The sera's heat inactivation offset any false-positive reaction at $56^{\circ} \mathrm{C}$ for 30 minutes in a water bath.

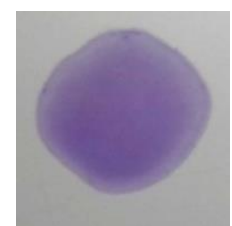

(a)

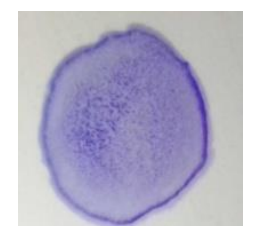

(b)

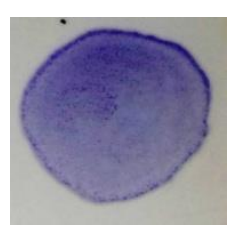

(c)
Fig. 1. Agglutination reaction scored (0) to (+++) (a, b and c).

\section{RESULTS}

From each flock five chickens were randomly selected for blood collection. $2 \mathrm{ml}$ of blood was collected aseptically from wing vein of each bird and then sera were separated and stored at $-21^{\circ} \mathrm{C}$ until use for serum plate agglutination test to determine the Seroprevalence of MG infection.The Seroprevalence of mycoplasmosis was calculated by considering total number of samples screened for mycoplasmosis and number of samples detected positive per formula.

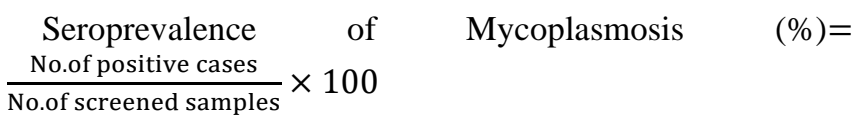

\section{A. M.gallisepticumAntibodies Detection by RSA}

A total of 800 sera samples were collected during winter and summer season from different geographical areas of Rajshahi district tested by Rapid Serum Plate Agglutination (RSA) test with commercial MG antigen.

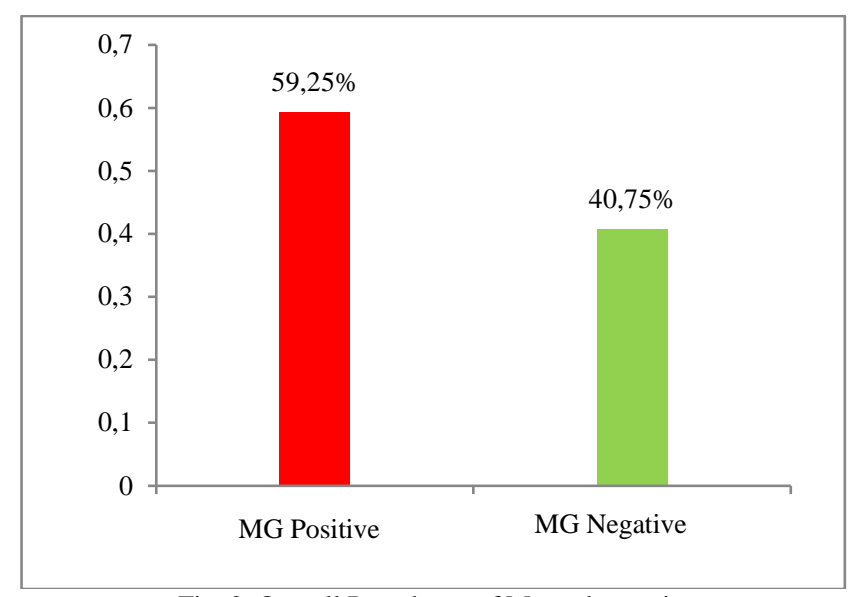

Fig. 2. Overall Prevalence of Mycoplasmosis.

The Seroprevalence of mycoplasmosis caused by MG was compared with respect to regions, seasons, age of birds and flock sizes and the test was performed in laboratory after collecting serum. Out of 800 sera samples tested 474 (59.25\%) were found positive by RSA (Fig. 2).

\section{B. Region Wise Seroprevalence of Mycoplasmosis}

Seroprevalence of mycoplasmosis was observed in two different geographical areas of Rajshahi district. Out of 800 sera samples from two different geographical areas 407 sera samples were collected from the Bagmaraupazila and 393 samples from Pabaupazila. In Bagmara 239(58.72\%) sera samples out of 407 were positive and in Paba upazila $235(59.79 \%$ ) samples out of 393 were positive. Highest Seroprevalence of mycoplasmosis caused by MG was observed in Paba upazila about 59.79\% (Table I, Fig. 3).

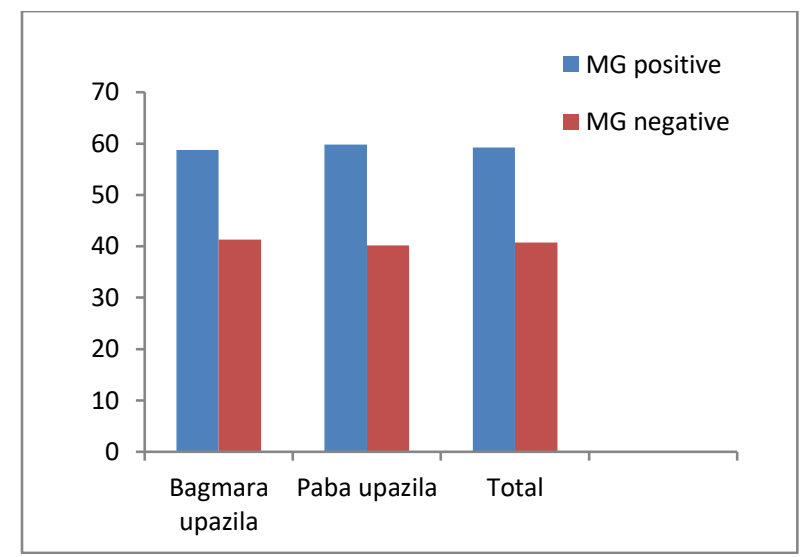

Fig. 3. Region wise Seroprevalence of Mycoplasmosis. 
TABLE I: REGION WISE SEROPREVALENCE OF MYCOPLASMOSIS

\begin{tabular}{cccc}
\hline $\begin{array}{c}\text { Geographical } \\
\text { Region }\end{array}$ & $\begin{array}{c}\text { Total sample } \\
\text { collected }\end{array}$ & MG positive & MG Negative \\
\hline Bagmaraupazila & 407 & $239(58.72 \%)$ & $168(41.28 \%)$ \\
Paba upazila & 393 & $235(59.79 \%)$ & $158(40.21 \%)$ \\
Total & 800 & $474(59.25 \%)$ & $326(40.75 \%)$ \\
\hline
\end{tabular}

C. Age wise Seroprevalence of Mycoplasmosis

800 sera samples of different ages of different layer birds were collected and grouped them to interpret age wise Seroprevalence of the disease. Total 125 serum samples were collected from birds between 10-20 weeks of age. And the Seroprevalence was $72 \%$ at the 10-20 weeks of age. Observed Seroprevalence in 21-30 weeks, 31-40 weeks, 41-50 weeks, 51-60 weeks, 61-70 weeks, and 71 weeks above was $68.14 \%$, $60.48 \%, 48.25 \%, 61.85 \%, 51.85 \%$, and $52.22 \%$ respectively (Table II, Fig. 4).

\begin{tabular}{ccccc}
\multicolumn{5}{c}{ TABLE II: AGE WiSE SEROPREVALENCE OF MG BY USING RSA TEST } \\
\hline $\begin{array}{c}\text { Age of } \\
\text { Bird } \\
\text { (Weeks) }\end{array}$ & $\begin{array}{c}\text { Total } \\
\text { sample } \\
\text { collected }\end{array}$ & MG Positive & MG Negative & $\begin{array}{c}\text { Level of } \\
\text { significance }\end{array}$ \\
\hline $10-20$ & 125 & $90(72 \%)$ & $35(28 \%)$ & \\
$21-30$ & 113 & $77(68.14 \%)$ & $36(31.86 \%)$ & \\
$31-40$ & 124 & $75(60.48 \%)$ & $49(39.51 \%)$ & \\
$41-50$ & 143 & $69(48.25 \%)$ & $74(51.74 \%)$ & 0.95 \\
$51-60$ & 97 & $60(61.85 \%)$ & $37(38.14 \%)$ & NS \\
$61-70$ & 108 & $56(51.85 \%)$ & $52(48.15 \%)$ & \\
$71-$ & 90 & $47(52.22 \%)$ & $43(40.74 \%)$ & \\
Above & & $474(59.25 \%)$ & $326(40.75 \%)$ & \\
Total & 800 & & & \\
\hline
\end{tabular}

$\mathrm{NS}=$ Nonsignificant at $5 \%$ probability.

** Significant at $5 \%(\mathrm{p}<0.05 \%)$.

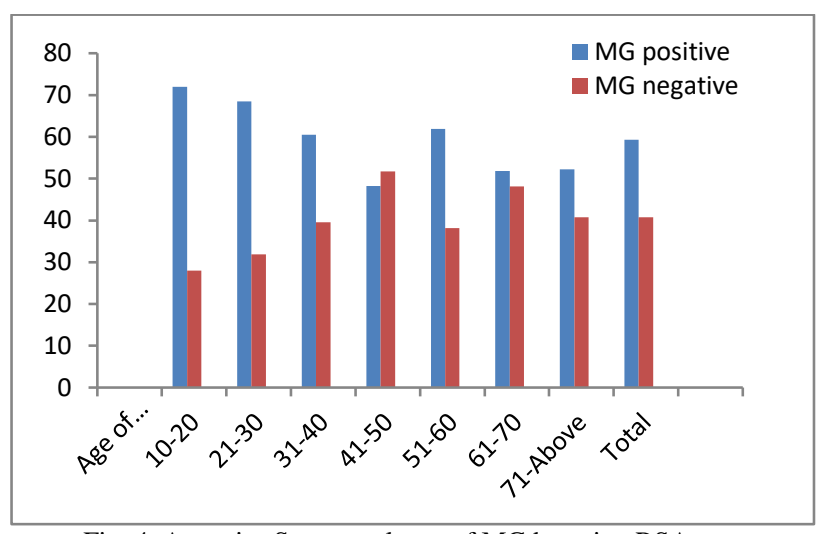

Fig. 4. Age wise Seroprevalence of MG by using RSA test.

\section{Seasonal Variation in Seroprevalence of mycoplasmosis}

A total number of 407 samples collected in winter and 280 were $(69.01 \%)$ positive for MG antibodies. 393 samples were collected in summer season, out of which 194 (49.49\%) were positive for MG antibodies (Table III, Fig. 5).

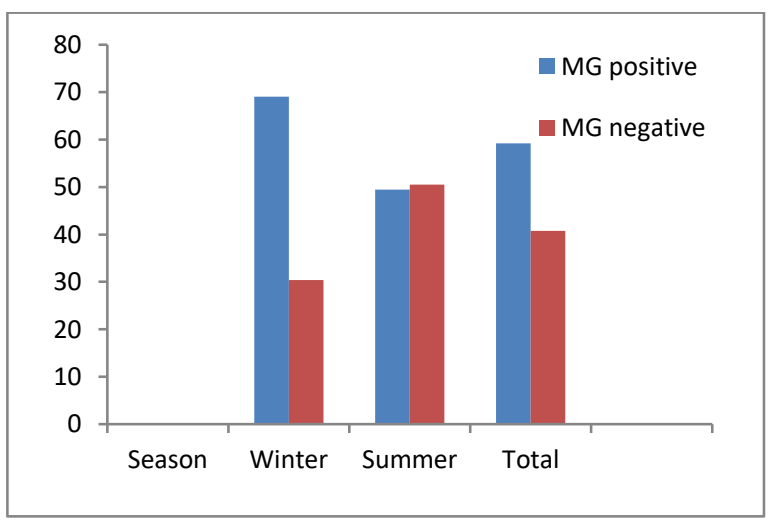

Fig. 5. Seasonal variation of mycoplasmosis.
TABLE III: SEASONAL VARIATION OF MYCOPLASMOSIS

\begin{tabular}{ccccc}
\hline Season & $\begin{array}{c}\text { Total } \\
\text { samples } \\
\text { tested }\end{array}$ & MG Positive & MG Negative & $\begin{array}{c}\text { Level of } \\
\text { Significance }\end{array}$ \\
\hline Winter & 407 & $280(68.80 \%)$ & $127(31.20 \%)$ & 0.0000000116 \\
Summer & 393 & $194(49.36 \%)$ & $199(50.64 \%)$ & $* *$ \\
\hline
\end{tabular}

\section{E. Flock Size Wise Seroprevalence of $M G$}

The highest infection rate was recorded $(69.01 \%)$ in large scale flocks (3001-3500) in comparison (53.63\%) to small size flocks having 500-1000 birds (Table IV, Fig. 6). Highest infection rate in large scale flocks probably due to the faulty management and bio-security.

TABLE IV: FLOCK SIZE WiSE SEROPREVALENCE OF MG

\begin{tabular}{ccccc}
\hline \multicolumn{5}{c}{ TABLE IV: FLOCK SIZE WISE SEROPREVALENCE OF MG } \\
Flock Size & $\begin{array}{c}\text { Total } \\
\text { Sample } \\
\text { Collected }\end{array}$ & $\begin{array}{c}\text { MG } \\
\text { Positive }\end{array}$ & $\begin{array}{c}\text { MG } \\
\text { Negative }\end{array}$ & $\begin{array}{c}\text { Level of } \\
\text { significance }\end{array}$ \\
\hline $500-1000$ & 138 & $\begin{array}{c}74 \\
(53.63 \%)\end{array}$ & $64(46.37 \%)$ & \\
$1001-1500$ & 132 & $\begin{array}{c}71 \\
(53.78 \%)\end{array}$ & $61(46.21 \%)$ & \\
$1501-2000$ & 134 & $\begin{array}{c}76 \\
(56.71 \%) \\
88\end{array}$ & $58(43.28 \%)$ & \\
$2001-2500$ & 139 & $\begin{array}{c}863.30 \%) \\
75\end{array}$ & $51(36.69 \%)$ & 0.0000088 \\
$2501-3000$ & 127 & $(59.00 \%)$ & $52(40.99 \%)$ & \\
& & 90 & $40(30.99 \%)$ & \\
$3001-3500$ & 130 & $(69.01 \%)$ & 326 & \\
Total & 800 & $474(59.25$ & $(40.75 \%)$ & \\
\hline
\end{tabular}

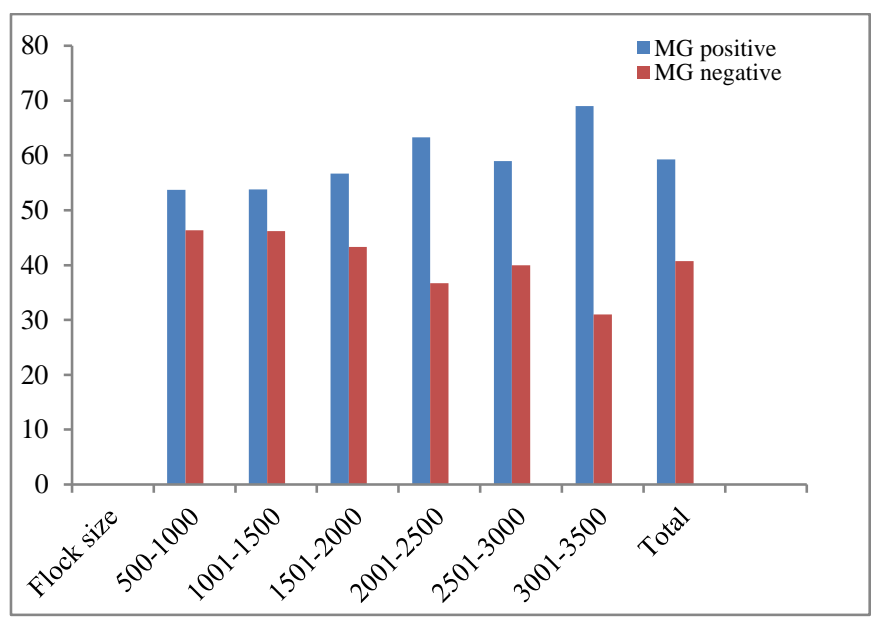

Fig. 6. Flock size wise Seroprevalence of MG.

\section{DISCUSSION}

Poultry is an emerging industry, and its progress is remarkable in Bangladesh. It has a bright prospect not only in Bangladesh but also in the whole world. Being a leading industry, it is contributing to the economic growth rate of Bangladesh. People of Bangladesh are getting inclined to this profession because of an unparalleled platform for a quick profit. So, it is now playing a major role in poverty alleviation. Despite this, it has some constraints, such as infectious diseases. Infectious diseases hampered poultry farming by its fatal outbreak. Avian mycoplasmosis is a kind of infectious disease which causes poor health condition and less in productivity, chronic respiratory disease, respiratory tract infection, and infectious sinusitis. It also causes considerable economic losses in chicken by reducing weight 
gain, lower meat quality, and the significant drop in egg production in layer birds. Taking the tremendous economic impact of avian mycoplasmosis in layer chickens in various regions of the Rajshahi district into consideration in our project, we endeavored to determine and develop a quick and efficient diagnostic platform.

800 sera samples were collected from the Rajshahi district were subjected to RSA test. Out of 800 sera samples, 474 $(59.25 \%)$ were found positive for MG. A case study on the Seroprevalence in Patuakhali district of Bangladesh was reported by $56.86 \% \mathrm{MG}$ infection in commercial layer chicken [10]. It was reported that $58.90 \%$ of cases positive for MG infection in some model breeder poultry farms in the Feni district of Bangladesh [11]. There were also reported of $69 \%, 60.25 \%, 56.54 \%, 59.10 \%, 57.15 \%, 54.90 \% \mathrm{MG}$ infection in layer chickens [12]-[15]. The parameter of age can influence mycoplasmosis. We have recorded age-wise seroprevalence, and the highest rate of MG infection, about $72 \%$, was seen in 10-20 weeks of age group followed by $64.86 \%, 58.71 \%, 55.52 \%, 48.89 \%, 47.43 \%$, and 45.36 in $21-$ 30 weeks, 31-40 weeks, 41-50 weeks 51-60 weeks, 61-70 weeks and 71-above weeks of age respectively. A similar observation was reported by $72.72 \%$ at $18-25$ weeks of age and lowest by $44 \%$ at above 66 weeks of age (Hossain et al., 2007). Equally increased vulnerability of younger birds to mycoplasmosis was demonstrated [10], [11].

During the winter season, seroprevalence of $\mathrm{MG}$ was recorded highest by $69.01 \%$ and lowest rate of infection as $49.49 \%$ during summer. It was noted that inclement weather such as cold and altered relative humidity could influence the seroprevalence. Our findings are relatively close, conforming to the earlier results [11]. The seroprevalence of MG was stated highest in the winter season [16]. Similar statements have been reported as $61.48 \% \& 61.45 \%$ in winter come after summer $47.7 \%$ \& $51.74 \%$, respectively [17], [10]. Regarding flocking density, the maximum infection of MG was recorded in large-sized flocks having a bird's density of 3001-3500 $(61.01 \%)$ compared to small ones $(53.63 \%)$. These findings have similarities with other scientists from Bangladesh [17], [18].

The highest infection rate in larger flocks might be correlated with poor management and bio-security measures in addition to horizontal transmission of the organisms from one bird to the other. During the farm survey, compromised management regarding bio-security was evident. So, the prevalence of Mycoplasma is higher where the management system is inadequate. Thus, the occurrence of mycoplasmosis and the excellent management system is negatively correlated.

In earlier, it has also been reported that the MG infection was more prevalent in the flocks kept under poor management conditions. The other contributing factors of high prevalence in the Rajshahi district might include the construction of poultry farms in close vicinity and the opportunity to recycle the pathogens to persist longer in the area. The other factors that may contribute to MG infection include inadequate ventilation, contamination of litter, and no restriction on the movement of technical staff and visitors from one farm to other as basic bio-security measures.

\section{CONCLUSION}

The highest Seroprevalence of MG was found in Paba upazila 59.79\%, and in Bagmaraupazila 58.72\%. Regarding age group, 10-20 weeks layer chickens were mainly affected with MG. In the winter season, MG infection was noted highest and, the infection rate was $68.80 \%$, and in the summer, it was $49.36 \%$. According to flock size, large size flock was more affected than other age groups. Therefore, more attention should be paid to age, season, and flock size because mycoplasmosis causes significant economic losses due to reduced feed conversion rate, egg production, and growth rate in layer birds in Bangladesh. Layer chickens affected by MG infection should be isolated, give proper medication, and eventually culled. Strict bio-security should be maintained for proper management of poultry farms and the prevention of infectious diseases by means of prophylactic treatment and vaccination. A detailed countrywide investigation is warranted for designing a comprehensive MG offsetting strategy in Bangladesh.

\section{ACKNOWLEDGMENT}

The authors gratefully thank the Quality Feed Limited, Bangladesh for rendering the technical support in carrying out all the research experiments in its facilities.

\section{CONFLICTS OF INTEREST}

The authors declare no conflict of interest.

\section{REFERENCES}

[1] Ley DH and Yoder HW (1997). Mycoplasma gallisepticum infection. In B.W. Calnek, H.J. Barnes, C.W. Beard, L.R. McDougald \& Y.M. Saif (Eds.), Diseases of Poultry $10^{\text {th }}$ edn. Ames, IA: lowa state University press USA. 194-207.

[2] Levisohn S and Kleven SH (2000). Avian Mycoplasmosis (Mycoplasma gallisepticum). Rev. Sci. Tech. 19 (2): 425-442.

[3] Allen CR, Mara A, Tulman ER, Ley DH, Geary SJ. House finch (Haemorhousmexicanus) (2018) - House finch (Haemorhous mexicanus)-associated mycoplasma gallisepticum identified in lesser goldfinch (spinus psaltria) and western scrub jay (aphelocoma californica) using strain-specific quantitative Polymarese Chain Reaction. J. Wildl. Dis. 54(1): 180-185.

[4] Bokhari SA (2003). Mycoplasma gallisepticum infection and prevention. Avian Research Center, University of Minnesota. Available http://www.cvm.umn.edu/avian/SFPC/Mycoplasma.html.

[5] Robinson TD (2012). Medical Microbiology (Eighteenth Edition).

[6] Bozeman LH, Kleven SH, Davis RB (1984). Mycoplasma challenge studies in budgerigars (Melopsittacus undulatus) and chickens. Avian Dis, 28: 426-434.

[7] Bradbury JM, Morrow C (2008). Avian mycoplasmas. In: Pattison M, McMullin PF, Bradbury JM, Alexander DA, editors. Poultry diseases, 6th ed. Philadelphia: Saunders Ltd. p. 220-234.

[8] Christensen NH, Yavari CA, McBain AJ, Bradbury JM (1994) Investigations into the survival of Mycoplasma gallisepticum, Mycoplasma synoviae and Mycoplasma iowae on materials found in the poultry house environment. Avian Pathology, 23:127-43.

[9] Kabir, A., Yasmin, M. S., Sarwar, M. G., Al Masum, M. O., Ahmed, S., \& Rahman, M. M. (2021). Evaluation of Antibiotic Sensitivity Against Bacterial Diseases Prevalent in Commercial Poultry Farm in Western Part of Bangladesh. European Journal of Agriculture and Food Sciences, 3(2), 69-76. https://doi.org/10.24018/ejfood.2021.3.2.262.

[10] Sikder AJ, Islam MA, Rahman MM and Rahman MB (2005). Seroprevalence of Salmonella and Mycoplasmagallisetpticum infection in the six model breeder poultry farms at Patuakhali district in Bangladesh. Int. J. Poult. Sci. 4 (11): 905-910. 
[11] Sarkar SK, Rahaman MB, Rahman M, Amin KMR, Khan MFR and Rahman MM (2005). Seroprevalence of Mycoplasma gallisepticum infection of chickens in model breeder poultry farms of Bangladesh. Int. J. Poult. Sci. 49(1): 32-35.

[12] Heleili N, Ayachi A, Mamache B and Chelihi AJ (2012). Seroprevalence of Mycoplasma synoviae and Mycoplasma gallisepticum at Batna Commercial poultry Farms in Algeria. Vet. World. 5 (12): 709-712.

[13] Haghighi PK, Akbariazad G, Roohi M (2011). Seroprevalence of Mycoplasma gallisepticum and Mycoplasma synoviae infection in the commercial layer flocks of the Center north of Iran. Afri. J. Microbiol. Res. 5(18): 2834-2837.

[14] Bencina D, Mrzel I, Tadina T and Dorrer D (1987). Mycoplasma species in chicken flocks with different management systems. Avian Pathol. 16(4):599-608.

[15] Godoy A, Andrade LF, Colmenares O, Bermudez V, Herrera A and Munoz N (2001). Prevalence of Mycoplasma gallisepticum in egg laying hens. Vet. Trop. 26: 25-33.

[16] Ali MZ, Rahman MM and Sultana S (2015). Seroprevalence of Mycoplasma gallisepticum antibody by ELISA and serum plate agglutination test of laying chicken. Vet. World. 8(1): 9-14.

[17] Hossain KMM, Ali Y,Haque MI (2007). Seroprevalence of Mycoplasma gallisepticum infection in chicken in the greater Rajshahi district of Bangladesh. Bangladesh J. Vet. Med. 5(1\&2): 9-14.

[18] Mukhtar MM, Awais M, Anwar MI, Hussain Z, Bhatti N and Ali S (2012). Seroprevalence of Mycoplasma gallisepticum among commercial layer in Faisalabad, Pakistan. J. Basic Appl. Sci. 8: 183186.

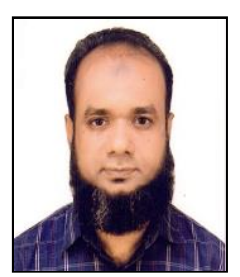

Aurangazeb Kabir an Associate Professor in the Department of Veterinary and Animal Sciences, University of Rajshahi, Bangladesh. He graduated on Doctor of Veterinary Medicine (DVM) and completed his Master of Science in Medicine from Bangladesh Agricultural University. He obtained his $\mathrm{PhD}$ from Gfiu University, Japan.

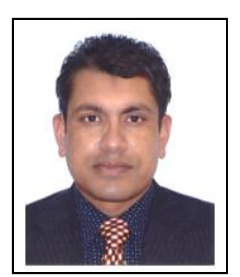

Mohammad Mahbubur Rahman a Professor in the Department of Veterinary and Animal Sciences, University of Rajshahi, Bangladesh. He earned Doctor of Veterinary Medicine (DVM) and Master of Science in Medicine from Bangladesh Agricultural University. $\mathrm{He}$ obtained his $\mathrm{PhD}$ from Milan University, Italy.

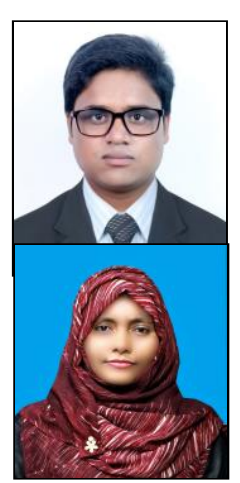

Md. Obaidullah Al Masum is graduated on Doctor of Veterinary Medicine (DVM), and completed master's degree in Medicine from the Department of Veterinary and Animal Sciences of Rajshahi University, Bangladesh

Most. Sabina Yasmin is graduated on Doctor of Veterinary Medicine (DVM) and completed master's degree in Medicine from the Department of Veterinary and Animal Sciences of Rajshahi University, Bangladesh.

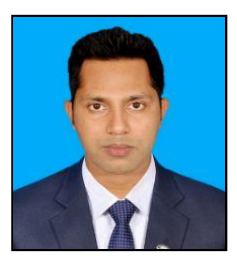

Md. Golam Sarwar is graduated on Doctor of Veterinary Medicine (DVM), and completed master's degree in Medicine from the Department of Veterinary and Animal Sciences of Rajshahi University, Bangladesh

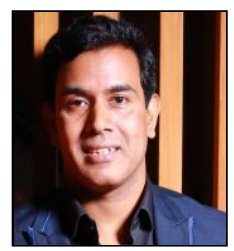

Soshe Ahmed is an Associate Professor in the Dept. of Veterinary and Animal Sciences. He is a graduate of BSc in Animal Husbandry and Master of Science in Poultry Science from Bangladesh Agricultural University, Bangladesh.

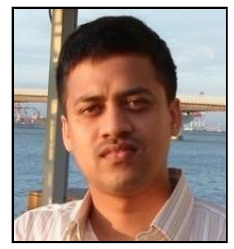

Md. Emtiaj Alam an Associate Professor in the Department of Veterinary and Animal Sciences, University of Rajshahi, Bangladesh. He graduated on Doctor of Veterinary Medicine (DVM) and completed his Master of Science in Medicine from Bangladesh Agricultural University. He obtained his PhD from Japan. 